\title{
Enacting Contextually Responsive Scholarship: Centring Occupation in Participatory Action Research with Children in India
}

\author{
*Tanya Elizabeth Benjamin-Thomas. BOT (Christian Medical College, India), MSOT (Colorado State \\ University, USA), PhD (University of Western Ontario, Canada). \\ https://orcid.org/0000-000 I-9830-3242 \\ Assistant Professor, Dr. Sophie Lin Rydin School of Occupational Therapy, Texas Woman's University, Houston, Texas, USA.
}

\author{
Debbie Laliberte Rudman. BSc. OT (University of Toronto, Canada), MSc OT (University of Western \\ Ontario, Canada), PhD (University of Toronto, Canada). \\ https://orcid.org/0000-0002-5486-8994 \\ Distinguished University Professor and Associate Director \& Graduate Chair, School of Occupational Therapy, Occupational Science Field \\ Leader, Graduate Program in Health and Rehabilitation Sciences, University of Western Ontario, London, Ontario, Canada.
}

\section{David Mark Thomas. BOT (Christian Medical College, India), MD (Central Michigan University, USA). https://orcid.org/0000-0002-7|43-3263 \\ Medical Resident PGY-I, The Dr. Kelly DeScioli Global Child Health Pediatrics Residency Program, Baylor College of Medicine/Texas Children's Hospital, Houston, Texas, USA.}

Occupation-based scholars are striving to mobilize socially responsive scholarship to address occupational injustices from local to global scales. Moving forward involves expanding beyond Western, Anglophonic, female, able-bodied, adult perspectives on occupation, with critically informed participatory methodologies providing one key means to incorporate diverse perspectives on occupation and occupational justice. Drawing upon a participatory action research project with children with disabilities from rural South India, this paper puts forward an understanding of participatory action research as an occupational process (i.e., embodying a variety of occupations) and an occupation-based process (i.e., informed by an occupational lens). We forefront how 'occupation' was centered and mobilized within the process of this participatory action research. In addition, drawing on select study findings, we illustrate and discuss how participatory action research provided a forum to partner with the child co-researchers and collaboratively identify and critically analyse occupational injustices. Through this illustration and discussion of participatory action research as an occupation-based process and occupational process, we demonstrate its potential to be used to enact contextually responsive scholarship and praxis.

Keywords: occupation-based participatory action research, occupational justice, occupation-based transformation, participatory filmmaking

\section{INTRODUCTION}

The increased integration of critical social theory within occupational therapy and occupational science has unpacked boundaries within which occupation has been conceptualized and addressed, particularly in the Global North. In turn, such work has identified the imperative to embrace plurality of ways of 'knowing' so as to enact contextually responsive scholarship that mobilizes occupation to transform society ${ }^{1,2,3}$. Critically informed scholarship has emphasized the situated nature of occupation, fore fronting occupation as shaped within historical and contemporary social conditions and power relations ${ }^{2,4}$. Such scholarship demonstrates that enhancing the social responsiveness and praxis of occupational therapy and occupational science requires moving beyond highlighting experiences of injustices, towards explicating and addressing the forces informing such injustices ${ }^{2,4-6}$. Moreover, given that occupation-based scholarship has been critiqued for narrow understandings of occupation and science aligned with Western, individualistic, post-positivist, Anglophonic, middle-class, white, adult, female, and able-bodied perspectives $^{7-11}$, power imbalances and ethnocentrism must be challenged ${ }^{7}$. This challenge requires not only critical reflexivity on taken-for-granted assumptions, but also embracing diverse perspectives on occupation to disrupt hegemonic understandings and move forward with reconfigured understandings and actions. Indeed, the analysis of occupation from diverse perspectives, particularly those of marginalized collectives, would promote a richer understanding of contextual forces that shape occupational injustices and guide collective praxis to counter-hegemonic practices and guide social transformation'.

The incorporation of diverse perspectives to challenge ethnocentrism and contemporary power relations embedded in the profession, requires methodological expansion, particularly further embracing of participatory approaches ${ }^{7,9}$. Critically informed participatory approaches can be mobilized in ways that dismantle postpositivist distinctions between science and action ${ }^{3}$, value all people as "equal knowers, thinkers, and do-ers"::12, and embody a commitment for collaborative praxis and social transformation ${ }^{3}$, 
all of which are considered essential for addressing occupational injustices in contextually responsive ways.

As one form of participatory research, participatory action research (PAR) embraces a commitment to working towards the ideal of equitable participation of community members as co-researchers and commits to enacting social transformation ${ }^{12}$. PAR embodies critical paradigmatic values that conceptualize injustices as shaped by unequal power structures and embodies an emancipatory agenda seeking to address injustices experienced by marginalized collectives ${ }^{13}$. As means to guide collaborative and contextually relevant transformative agendas, PAR centres local knowledge and expertise to understand context as lived and experienced ${ }^{14}$. Although the potential of PAR for socially transformative occupation-based research has been discussed ${ }^{15,16}$, we argue that its relevance can be further mobilized given its potential to be taken up in ways that center occupation in its process as well as in its aims for knowledge generation and praxis. More specifically, PAR provides a space for praxis that centres and mobilizes occupation towards social transformation, which in turn facilitates collective generation of contextually relevant knowledge regarding occupational injustices and their socio-political production.

The broad purpose of this paper is to highlight the potential of centring occupation within PAR. More specifically, we forward an understanding of PAR as an occupational process (i.e., embodying a variety of occupations) and an occupation-based process (i.e., informed by an occupational lens). We demonstrate the critical and transformative potential of such an approach through integrating illustrations from a PAR project with children with disabilities from rural South India that centred occupation. We first provide an overview of the study context and research team, and highlight how occupation was at the core of this PAR process. Following which, we demonstrate how this occupation-centred PAR provided a forum for collaboratively generated, contextually embedded knowledge about occupations and occupational injustices. We also address the ways in which this PAR raised critical consciousness among co-researchers, research facilitators, and community members about socio-political forces at play within the study context and their implications for occupation, and how this approach mobilized avenues for transformation ${ }^{17}$. Further details regarding other aspects of this study, including how it further engaged other community members and stakeholders within the context, how critical reflexivity was centred, and its key findings, are reported elsewhere ${ }^{17-19}$.

\section{METHOD}

\section{Design: Participatory Action Research with Children with Disabilities in rural India}

Prior to focusing on how we conceptualized and enacted PAR as an occupational process and an occupation-based process, we briefly introduce the study ${ }^{17-19}$ we will draw on to illustrate this approach to PAR. A three-phased PAR, inclusive of preparatory, participatory research, and action phases, was carried out with children with disabilities from a rural village in Southern India ${ }^{19}$. To facilitate inclusion of children with disabilities as co-researchers, participatory filmmaking ${ }^{20}$ was used. Child co-researchers created a short film to document, explore, and critically engage with occupational justice issues, situating them in socio-political conditions ${ }^{19}$.

\section{Research Context and PAR Research Team}

Entry into the study context was enabled by the first author's relationship, established when she was previously an occupational therapy student, with the department of community health at a medical college and hospital in Southern India. The village in which the PAR was conducted was selected from those served by the community health department and informed by this department's records regarding the number of children with disabilities.

Child co-researchers were invited into the study via linguistically and culturally relevant posters and recruitment meetings within their community. To participate, child co-researchers required sufficient cognitive skills, ability to communicate verbally in Tamil or non-verbally with or without the use of an assistive device, and interest in using a camera to share their experiences. Six male children with disabilities, aged 10 to 17 , participated as co-researchers. Five were attending school, two in the local public school, one in school for children with speech and hearing impairments, and two in a residential institute for children with disabilities. All child co-researchers were identified by a local health care provider or community member as experiencing some form of impairment (visual, intellectual, speech and hearing), although not all had a formal medical diagnosis. Although six children participated within this PAR, only three of them were consistently involved in creating the participatory film due to barriers to full participation ${ }^{17}$. Within this article, pseudonyms are used when referring to these co-researchers.

\section{Ethical Clearance}

Ethical clearance was obtained from the Western University Health Sciences Research Ethics Board, London, Canada (Project ID: I I 09/2) and the Institutional Review Board Christian Medical College, Vellore, India (IRB No: III9I).

This PAR was carried out within the scope of the first author's PhD thesis within the field of occupational science from a North American institution. This project was informed by her prior experiences in practice as a paediatric occupational therapist in rural India where she witnessed situations of occupational injustices experienced by children with disabilities, who were often denied opportunities for participation within school, home, and community settings. The first author facilitated all meetings with child co-researchers in their local language, Tamil, which is also her native language. Although the first author was from the same ethnic background, familiar with the local language and context, she had to constantly navigate her role as both an insider and outsider2 I holding different life experiences. Additionally, a local professional photographer supported the first author with the training of child co-researchers in camera-related skills as well as in co-facilitating some group discussions with child co-researchers.

\section{Situating 'Occupation' in the Forefront of Participatory Action Research}

Within rural Indian contexts, power differentials between adults and children are prevalent. Children are often not provided with the space to express their thoughts and emotions, and are expected to abide by adults' perspectives on what is best for them ${ }^{22}$. Given that PAR embodies the central tenet of equitable participation, involving children as collaborators required challenging existing power differentials. Doing occupations together provided a space to disrupt these differentials and build more equitable relationship. More specifically, child co-researchers and research facilitators engaged in numerous culturally relevant games such as signal relay, hide and seek, dancing to local music, tag, follow the leader, and cricket.

This PAR also aimed to embody an occupational perspective, defined as "a way of looking at or thinking about human doing"23:233, as means to explore and address everyday injustices. One 

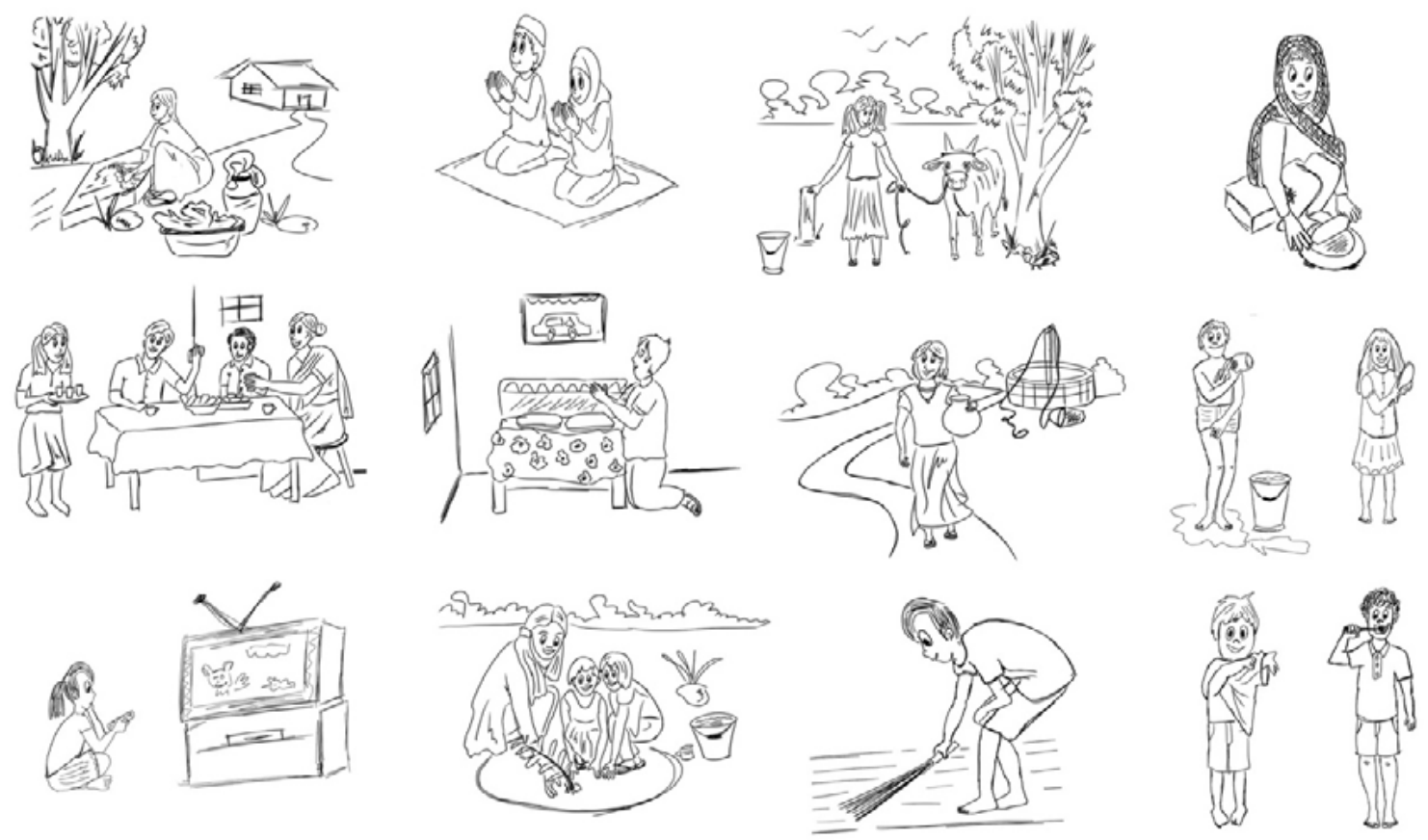

Figure I: Occupations within Home Environment.
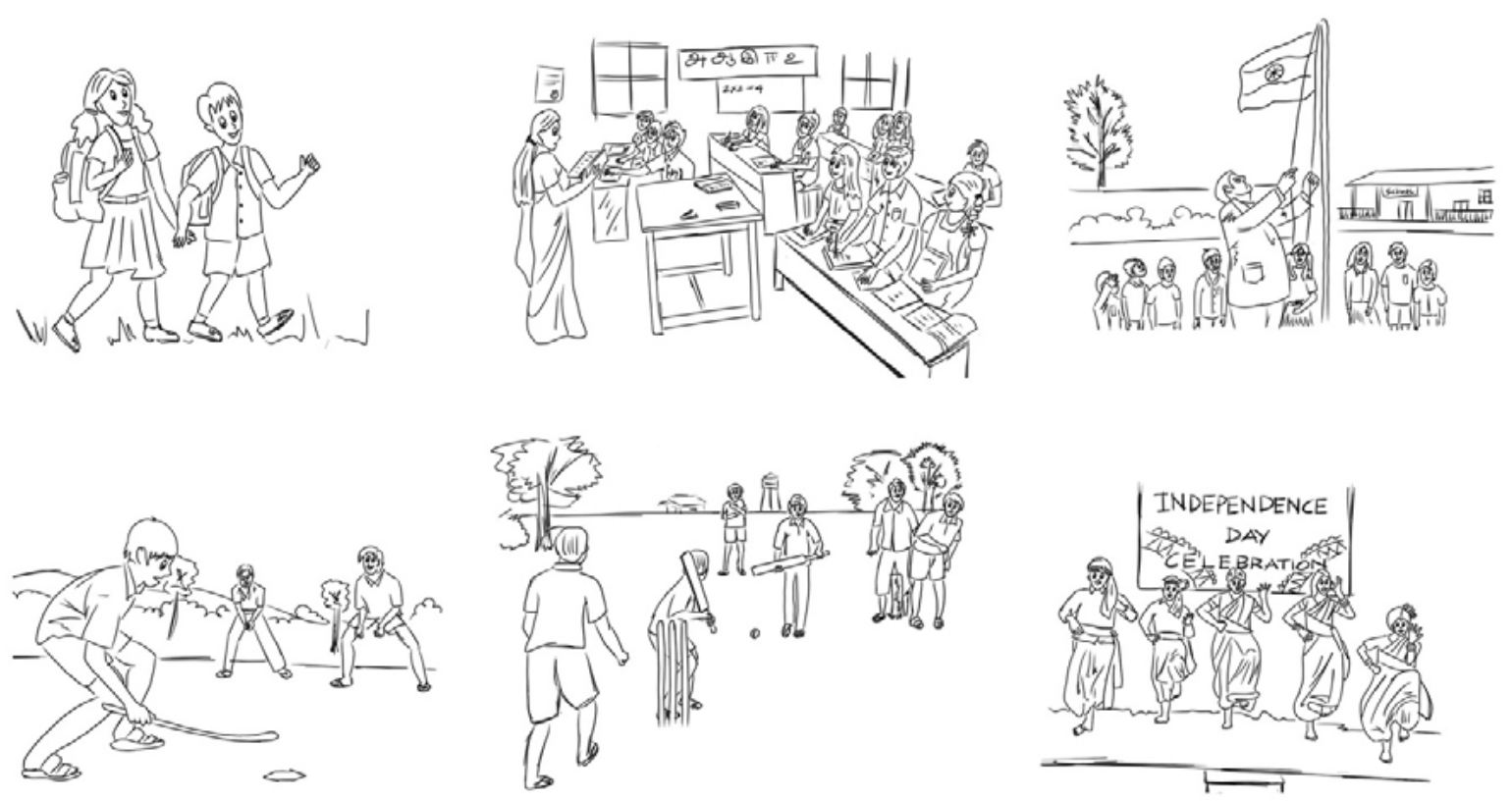

Figure 2: Occupation within School Environment.

contextually specific challenge was that the construct 'occupation' lacks literal translation in Tamil. To support child co-researchers in using an occupational perspective, discussions on everyday doing were facilitated using culturally relevant visual illustrations. Given a dearth of context specific visuals, these illustrations, drawn by the third author, were informed by shared discussions with the first author based on their experiences as occupational therapy students and practitioners in rural Indian settings. These visual illustrations encompassed individual as well as collective occupations within home, school, and community environments, and aimed to reflect context specific diversity in terms of religion, attire, and occupations (See Figures. I, 2, 3). For example, in Figure I, occupations such as fetching water, a resource that needs to be collected on a regular basis from public taps using pots carried by women on their waists, is illustrated alongside an image of women engaging in the occupation of washing clothes by hand often done in outdoor spaces in squatting. Similarly, in Figure 2, culturally relevant games such as cricket and gilli-danda*, commonly played by boys within this context, are highlighted.

Child co-researchers individually sorted these visual illustrations to highlight and discuss occupations they enjoyed doing and occupations they did not enjoy doing as much. These illustrations and dialogue helped situate 'occupation' within the forefront of this PAR process as child co-researchers became familiar with the

*A game played by children using a round stick (danda), which is used to hit a small oval shaped piece of wood (gilli). 

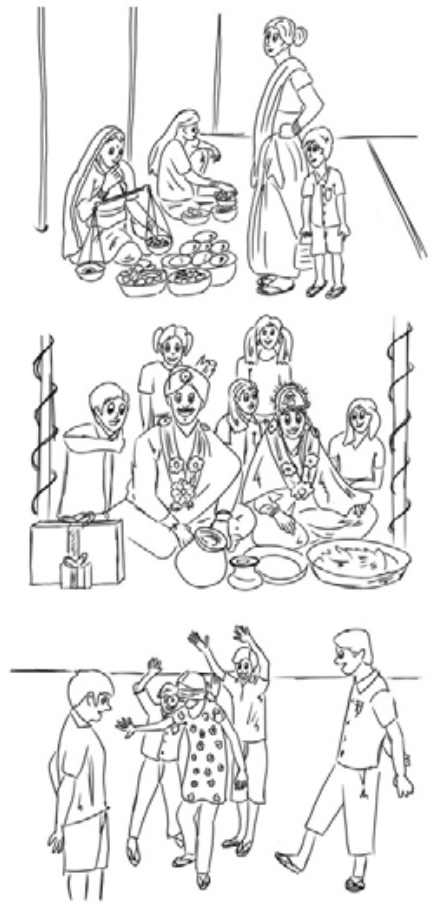

Figure 3: Occupation within Community Settings.

construct of 'occupation,' discussed occupations that were within and not within illustrations, and prioritized occupation-based issues they wanted changed for themselves and for their community. After child co-researchers identified and prioritized issues, they decided on participatory filmmaking as their research methodology of choice ${ }^{19}$. Participatory filmmaking, a process where community members engage in a process of creating videos to document and address social issues, is rooted within Paulo Freire's work on critical pedagogy that seeks to address injustices through shared dialogue and the raising of critical consciousness ${ }^{24}$. Numerous occupations were included within this participatory filmmaking process. Child co-researchers conducted guided walks within their community to further explore issues they prioritized, they captured video footage, watched the video footage, engaged in shared dialogue, and worked with the first author in creating, editing, and disseminating the short film. This occupational process facilitated in-depth participatory explication of occupational issues, while continuing to build relationships amongst PAR team members.

Overall, the data generation process among child co-researchers was participant-driven and dialogic, with occupation placed at its center ${ }^{20,25}$. Child co-researchers engaged in approximately 35 group meetings that involved participating in occupations and shared dialogue on occupation-based issues they considered relevant to their lives and as priorities for change. The collaborative dialogic analysis involved cycles of discussions among child co-researchers addressing prioritized issues, followed by capturing videos based on discussions, collective viewing of captured videos, and further engaging in shared dialogue to explicate how identified occupational injustices were embedded within socio-political, cultural, and economic forces ${ }^{26}$. Moving between shared dialogue and collective occupations created a process that sustained engagement. Shared dialogue among child co-researchers was informed by Freire's work ${ }^{24}$ that situates shared dialogue among collectives experiencing injustices as essential for explication and action addressing the contextual forces shaping and perpetuating situations of oppression ${ }^{26}$. More details about this occupation-centred process and knowledge generated by child co-researchers through their created short film is publicly available (https://youtu.be/sPyiQCj82Qs).
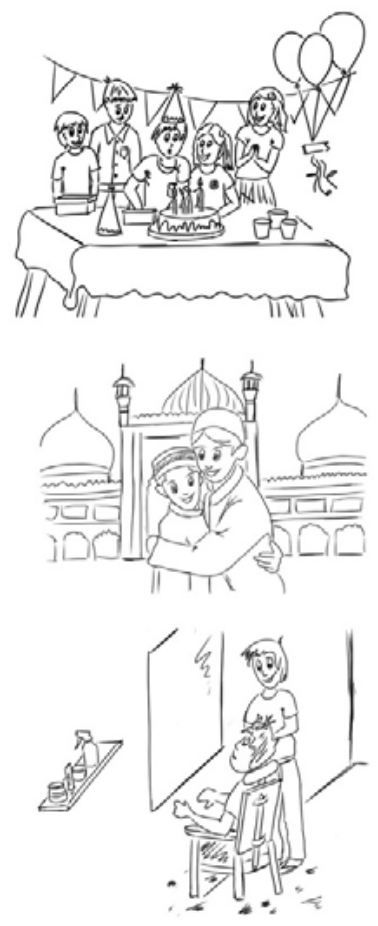

\section{FINDINGS}

\section{Collaborative Dialogic Analysis: Explicating Occupation and Occupational Injustices}

In this section, we briefly discuss select findings of this occupationbased PAR to highlight how this process provided a space for collaborative knowledge generation and action addressing occupation and occupational injustices. The themes that emerged (see Table I p26) broadly highlight how child co-researchers attempted to navigate desired occupations within existing boundaries; occupational injustices experienced by children with disabilities connected to marginalization in schools, homes and the community; and occupational injustices at the community level highlighting interrelated issues of substance abuse and violence as well as issues of occupational degradation.

\section{Navigating Desired Occupations within Existing Boundaries} Findings illustrated the complex navigation processes engaged in by the children as a means to navigate desired occupations, thus contributing to the knowledge base regarding the situated and relational nature of occupation. As one example, child co-researchers discussed various barriers to occupational participation, highlighting parental resistance, which was described as parents' efforts to protect them from community violence. For instance, Karthi articulated, "I want to go somewhere with my friends but they [parents] won't let me go. They consult an astrologer and based on that, they tell me, 'don't go out, someone will do something to you'... They say, 'you don't go anywhere, or you'll end up in a fight."' Additionally, issues of violence associated with child trafficking further restricted their occupational participation. Sanjith described that his mother often refused to let him outdoors due to the presence of child traffickers in their neighbourhoods, "She keeps saying "people have come to catch kids, so be quiet and stay back at home."' Shivam further contextualized the issue expressing that the political system was unable to protect children of all ages, and that parents needed to be cautious even for older children: "Apparently the police also don't do anything, they only catch them and let them out in another location. 
Table I: Summary of Findings (themes and sub-themes) from the Occupation-Centred PAR Process.

\section{Occupational Engagement of Children with Disabilities}

Navigating Desired Occupations within Existing Boundaries

Occupational Injustices Experienced by Children with Disabilities

Marginalization within School, Home, and Community Settings

Occupational Injustices Presented as Community Problematics

Substance Abuse and Household Violence

Teasing and Bullying among Children

Issues of Occupational Degradation

\section{Transformation through Occupation}

Sensitization of Community Members and Service Providers

Challenging of Negative Perceptions associated with Disabilities

Personal Transformation of Members of the Research Team

New Community Program Initiatives

They don't put them in jail or anything."

Within this context where concerns about violence were prevalent, child co-researchers described that they felt like they lacked autonomy and desired a space for decision making regarding their occupational participation. For example, Karthi shared, "What I am trying to say is that, when we do something, people [family members] should not keep telling us 'you don't do this' or 'don't do that'... Everyone needs to be able to do what they want, like everyone makes decisions for us...."

Other contextually shaped barriers to occupational participation forwarded by child co-researchers included a lack of playgrounds within their community as well as economic constraints. Karthi, pointed out that playing games on the streets, such as cricket, was not accepted by many community members. He then shared, "We need a ground to play in, because where we play now is full of thorns... Some people don't like it when we play close to their house and make a noise, or if our ball hits their house and breaks a window, because sometimes we play on the streets. "Shivam, who was interested in music, pointed out the economic constraints faced by his family, "I just don't know how to play it [musical instrument] ...My mother is also thinking of joining me for classes [music], even if it's there, it costs a lot..."

However, although facing these various types of barriers, child co-researchers described various occupations they enjoyed doing such as playing local games like cricket and carrom board, playing music with friends, doing chores like fetching water, and worshiping in the temple. Desired occupational participation was connected to building relationships and a sense of inclusion. As Shivam described, “... I really like playing the local drums... I usually don't play the drums alone but only when there are two or more people to play with me."

\section{Occupational Injustices Experienced by Children with Disabilities}

Centring occupation within this PAR process facilitated an approach through which child co-researchers described occupational injustices by pointing to their experiences of marginalization within schools, homes, and communities. Moreover, the occupational process employed enabled working with the children so as to situate these injustices within socio-political, economic, and cultural forces, further deepening understanding of occupation as situated, relational and political.

\section{Marginalization within School, Home, and Community Settings}

One key type of injustice identified was related to experiences of being marginalized within various types of settings. For example, within schools, child co-researchers described restricted opportunities for participation within cultural programs and sports activities. Such exclusion was often framed as intentional acts of teachers driven by their negative perceptions of the children's capabilities. Shivam described that teachers excluded him from participating in track and field events as well as in dance events by saying that his "glasses will fall off.” Similarly, Karthi added, “... If I volunteer myself for something, they say, 'we don't want you' and call others... They used to say 'you will not do it well'..." Moreover, child co-researchers indicated that they were further marginalized in classroom activities when their academic performance was considered inadequate by teachers. For example, Sanjith shared, "They [teachers] will hit me saying, 'why didn't you get any marks? And if you're not getting any marks, why are you coming to school?' They will also make me sit separately...."

These experiences of exclusion and marginalization affected the emotional, and in turn, educational experiences of child coresearchers. Karthi described how he navigated some of these emotions and shared, "I used to feel sad... Those participating will go be involved, and those not participating will be with me. But I won't show it on the outside that I am feeling bad..." These experiences contributed to him dropping out of school.

Experiences of marginalization also extended into their home and community environments. Karthi shared that he was marginalized at home because he had dropped out of school, and that within community settings he was denied opportunities to play games alongside his peers due to perceived notions of his incapability: “... they treat me like my hands don't work and my mouth does not work, they say, 'we don't want you' and ask me to leave..."

\section{Occupational Injustices Presented as Community Problematics}

Extending out from individual experiences of occupational injustices, centring occupation in the discussions supported child coresearchers in discussing community occupational issues related to substance abuse practices and inter-related forms of violence, as well as environmental issues. Child co-researchers' dialogue and interests in addressing such community-based issues challenge dominant assumptions embedded in occupation-based literature that place occupational injustices at the individual leve $\mathrm{l}^{15}$ and opened up possibilities for contextually responsive understandings of occupational injustices as collective injustices.

\section{Substance Abuse and Household Violence}

Substance abuse practices were positioned by child co-researchers as contributing to other occupational issues of violence within their communities. Specifically, poor household economic conditions were said to contribute to substance abuse by adult men within their community which, in turn, was highlighted as a predominant factor contributing to household violence. As Shivam put it, "Someone said, if there is a stone in the rice, then they [men] will beat their wives, but if there is a lizard in the alcohol, they will throw it out and drink it." Child co-researchers also pointed to how substance abuse contributed to financial strains within households, as Shivam described, "My father also drinks a lot! ... at night he will come and fight with my mother, he has a lot of loans because of drinking, and he will keep asking my mother for money, and my mother won't give him money, so he will hit her..."

These occupational patterns of adults were described by child coresearchers as becoming engrained among young people within their community, both through watching adults and by exposure to substances during local festivals. Sanjith mentioned, "They watch their father and learn... Another thing is, in festivals many people drink, 
so small children watch that and start drinking." Child co-researchers further contextualized the use of substances by children to other occupational practices such as improper practices of garbage disposal. For example, Sanjith, during guided walks in the community, described how children experimented with substances disposed in public spaces within their village: "5-10-year-old children, as soon as they see bottles lying around. They keep it in their mouths and drink from it, even if there is only little... They pick up small buds and put it in their mouths"

Overall, through shared dialogue, child co-researchers collectively generated an understanding of substance abuse practices as a systemic problem exacerbated by poverty, government-run establishments selling substances, improper garbage disposal practices, and entrenched occupational patterns across generations. Child co-researchers articulated how many community members were stuck within this practice, including people in power, and thereby, requiring more than individual change to address this complex issue. As an example, Sanjith called for shutting down all liquor stores by articulating, "We should not have Brandy shops, if they exist the men will get spoiled" and Shivam added, "if we remove them, many of our issues will get solved."

\section{Teasing and Bullying among Children}

As child co-researchers discussed issues of teasing and bullying amongst children through engaging in occupations involving storytelling and acting, they drew connections with the broader context of community and household violence. Specifically, engagement of adults in household violence seemed to cycle into other forms of violence, including teasing and bullying among the children, which in turn, further shaped occupational injustices in school, homes, and communities.

Child co-researchers described and acted out their experiences of being teased by peers within as well as outside of school contexts, which impacted their occupational participation within those contexts. They expressed being deliberately made fun of by their peers because of an impairment, use of an assistive device, or not performing activities according to a perceived norm. For example, Shivam was teased and called names such as "glasses, grandma glasses, cooking batter to make idlis [round shaped rice cake]....". Sanjith also shared experiences of another child with a speech and hearing impairment who was teased, "They call [name] by calling him 'deaf and dumb'... and also by just mimicking his voice 'mmm' 'mmm'... They verbally abuse him, as he can't hear, they say so many things..."

As described by child co-researchers, teasing escalated into bullying, where children with disabilities were intimidated as well as mistreated physically and verbally by their peers. Shivam shared, "When I am sitting quietly in school, they come and say "hey glasses, grandma glasses, come and fight with me if you have courage! They simply annoy me... they will also hit me." Similarly, Karthi described, "Children my age will join the older guys and do this. When I am simply walking, they throw stones purposefully and scold without any reason... They say very mean things, like talk about my mother and all."

Occupational issues related to teasing and bullying were situated by child co-researchers within broader community violence as well as larger contextual issues of discrimination experienced by many children on the basis of diverse attributes. As an example, Karthi discussed the gendered nature of teasing, and commented, "They behave badly with girls, and tease girls." Sanjith also pointed to how he was teased because his dark complexion, "They mock me and say, 'get lost you dark crow!'” Additionally, teasing and bullying were positioned by child co-researchers as an issue prevalent throughout the life course and not only among children. They suggested that the language used by adults contributed to instances of teasing practiced by children. Karthi noted, "The adults themselves speak like that... Some people think it's fun! They learn it from others, watching others..."

\section{Issues of Occupational Degradation}

Through the use of dialogue centred on occupation, issues of occupational injustices were further situated by child co-researchers in relation to broader environmental issues. Specifically, deforestation and garbage accumulation practices were described as impacting on, and impacted by, their own occupations and those of the community.

Garbage accumulation within village public spaces, streets, temple spaces, public wells and rivers was positioned by child coresearchers as an issue that needed to be addressed. Sanjith took the PAR team to a shop and problematized how community members eat from local shops and discard garbage on the streets. Shivam identified various wells in the village and shared that "The common wells, nobody cleans it, they just throw garbage.... Near the temple, there are a lot of bottles and water packets...." Child co-researchers discussed how these improper garbage disposal practices affected livestock, plants, as well as health and well-being of community members. More specifically, occupational engagement of community members in leisure activities such as swimming in public wells was hindered due to the accumulation of broken glass and other garbage. Improper garbage disposal practices were inter-related with substance abuse practices. In addition to discussing how improper garbage disposal was a contributing factor for initiating substance abuse practices among children, child co-researchers posited that substance use practices were also contributing to garbage accumulation in public spaces. Sanjith shared, "People drink and throw it [bottles and packets] right here at night so nobody sees them drinking."

Child co-researchers, through engaging in shared dialogue, situated garbage accumulation as a socio-politically shaped issue. They discussed how certain community practices, such as those surrounding funeral rituals, pushed for garbage disposal and other material in public spaces, and how systemic corruption and constraints hindered community members from engaging in proper garbage disposal. Sanjith pointed to the irregularity of garbage collecting vehicles, "The garbage vehicle doesn't come into the inner village streets. It only goes on the main roads... If the garbage vehicle doesn't come regularly, they throw it in the well..." Additionally, Karthi pointed to potential corruption: "Only when the councillor is coming, they will start cleaning the place until they come and see it, after that it goes back to normal."

Occupational degradation in relation to deforestation activities within their village were discussed as having consequences for flora, fauna, and occupational engagement of community members. The child co-researchers contextualized deforestation practices within existing needs and occupations, such as space and wood for building houses, cooking, and safety reasons. For example, Karthi described, "They are cutting a lot of trees in our village... Some people say they need it for work and cut down trees. They cut trees and use it for their stoves." With regard to safety, outdoor electric wires often got entangled with tall trees and the cutting of trees was then considered necessary. Shivam explained, "In my house they were worried about the wire that the tree was touching, so they cut it off." While child co-researchers discussed how some deforestation activities 
in relation to safety were necessary, they also expressed concerns. Karthi discussed water shortage issues, as deforestation reduces rainfall: “... and we don't get enough water. Even in my house we get water only once every two days..." Additionally, a need for shade and breeze from trees was considered essential for community members when engaging in outdoor occupations. Karthi shared, "The shade provides us a place to sleep, eat, as well as to cook food."

\section{Transformation through Occupation underpinned by PAR}

Enacting transformation is a central tenet of $P A R^{12}$. Based in our experiences of doing this occupation-based PAR, we found that this approach encompassed a continuum of processes from personal to societal levels. Through dissemination of the short film, community members and service providers were sensitized to community problematics identified by child co-researchers as well as to capabilities of children with disabilities, which led to the motivation of parents, health care providers, and village leaders to address issues forwarded by child co-researchers. 'Disability' within this research context has been linked to perceptions of 'incapability' and 'lower status' ${ }^{27}$. However, the children with disabilities involved within this PAR as co-researchers resisted and challenged the negative taken-for-granted assumptions regarding their positioning in society through engaging in occupations that were part of the PAR process. They positioned themselves as talented and capable social actors and teachers through this PAR process, irrespective of what their family members, peers, or the larger community thought about their abilities. Through their short film, parents, service-providers, and community members recognized the occupational potential of child co-researchers, who shared about issues that needed to be addressed both for themselves and their community and demonstrated competence in various occupations. A parent shared, "These children have many talents, and we have now seen that. What we don't know, the children have shown us...." Child co-researchers motivated and instilled hope, among parents and health care providers, highlighting that change is possible within their community. In turn, parents, health care providers, and community members articulated an enhanced motivation and shared responsibility to address situations of occupational injustices faced by children with disabilities as well as issues of collective occupational injustices. Another parent articulated, “... Only now can I understand your feeling. I can now know how you feel when you go to school... and all the problems you are facing... We have seen garbage only on the roads but not inside the wells and the fields. Now we have seen that... and we need to try and rectify all these issues."

Another finding was that through engaging in the occupations comprising this PAR process, members of the research team also expressed personal transformation. In addition to obtaining technical skill sets in working cameras and the computer, child co-researchers described gaining courage and self-confidence to speak up, stand up for their rights, and address community problems. For example, Karthi described, "Before, none of us spoke that loudly or openly, but now we have gained some courage... We have the courage to tell people not to throw garbage when we see them, or not to cut trees. I have gained courage to speak up for things like this." Shared dialogue supported increased knowledge among child co-researchers as well as facilitators on topics discussed within this PAR. Additionally, through the on-going process of critical reflexivity, a particular poignant point of personal transformation for the first author involved enhanced awareness and challenging of her implicit assumption, perhaps shaped through her education experiences in North America, that occupational injustices are experienced by individuals. Indeed, at first, the first author grappled with understanding why children were speaking about community issues rather than their own individual experiences of injustices arising from having an impairment, and through dialogue came to understand how the children were framing collective issues as occupational injustices with complex implications for various actors and aspects of their communities. Overall, these attitudinal changes can be interpreted as both transformation at the individual, personal level, but also at a collective, social level.

Child co-researchers also proposed community initiatives and programs. For issues of teasing and bullying, they called for educational programs encompassing simulation where children could engage in such situations as "They should understand how it feels if the same thing would happen to them. They themselves need to think about it..." as Karthi put it. Addressing issues of occupational degradation, Shivam called for training activities where community members are shown through doing how to sort garbage. Furthermore, occupation-based competitions and programs such as tree planting initiatives were called for to push community members to intentionally grow more greenery within their village. Some of these programs have started to be implemented by the community health department of the local institution in collaboration with the local village leaders ${ }^{17}$.

\section{DISCUSSION}

PAR, as reflected through this work with children with disabilities as co-researchers, can be positioned as an occupational process, embodying a variety of occupations and directed towards generating knowledge and addressing occupational injustices. In this project, in addition to child co-researchers embodying an occupational perspective where 'occupation' was the central construct of focus, various occupations such as filmmaking, discussions, games, and guided walks were embedded within the PAR process. In turn, we position this PAR as an occupation-based PAR, which created a space for child co-researchers to identify, critically discuss, and address situations of everyday injustices that extended from individual experiences to community problematics. According to Angell, occupation is "not only a means of resistance and change but also a site where inequality and social difference are constituted"5:105. An occupation-based PAR can position research as a site for resisting inequities and create spaces for generating contextualized understandings of issues of everyday injustices experienced by individuals and collectives.

The positioning of PAR as an occupational process has also been forwarded by Crabtree and colleagues ${ }^{28}$ who reflected on a PAR carried out in a prison setting, pointing to how it addressed situations of occupational deprivation among prison inmates. Building on this work, we have further situated PAR as an occupational process and have drawn attention to the transformative potential of an occupation-based PAR. We invite occupation-based scholars to continue this dialogue and innovatively take up this research approach as means to further the understandings of the situated nature of occupation and occupational justice within diverse contexts and address change in a contextually responsive manner. Doing so requires underpinning occupation-based PAR within a critical paradigm in order to address the socio-politically constructed roots of occupational injustices ${ }^{4-6}$, and engaging in on-going critically reflexivity to create openness to diverse worldviews and a willingness to challenge taken-for-granted assump- 
tions. Critical reflexivity, an "approach to reflection that focuses primarily on the politics and ideologies embedded within research processes and within the self of the researcher"29:8 is imperative to not only guide ethical research practices ${ }^{30}$ but also to enact contextually responsive scholarship. The lead author engaged in self reflexivity as well as engaged in shared reflexivity with the research co-facilitator and child co-researchers throughout the research process. For the first author, who carried out this PAR as part of her $\mathrm{PhD}$ dissertation, engagement in this project involved on-going critically reflexivity on her positioning as an occupational therapist who received her professional degree from India. Within her education, she primarily engaged with occupational therapy material through books and articles published within an Anglophonic, North American, minority world context. In turn, her perceptions about the needs of children with disabilities is based on her educational experiences as well as practice experiences as an occupational therapist and her upbringing as a middle-class urban Indian woman. The needs she perceived as important and requiring immediate action, that is addressing individual experiences in relation to disability, were different from what child co-researched perceived as important, that is larger community issues. These tensions further informed the need for her and other team members involved to continually practice critical reflexivity acknowledging their values, positioning, and assumptions in relation to this PAR, and embrace cultural humility.

Within this PAR, a critical occupational perspective ${ }^{31,32}$ supported collaboratively generating understandings of the situatedness of everyday injustices experienced by child co-researchers and their communities by attending to power relations that shaped axes of privilege and disadvantage in relation to occupation. This process can be connected to an awakening of occupational consciousness, generating enhanced awareness of hegemonic power relations shaping everyday life ${ }^{33}$. Within this occupation-based PAR child co-researchers situated occupation and occupational injustices within socio-political contextual conditions and mobilized a collective viewpoint, coherent within their context, such that issues of justice were not predominantly framed as matters of autonomy and individual choice as within dominant Western views ${ }^{34}$. Rather, occupational injustices were positioned as embedded within contextual forces of power imbalances, systemic corruption, poverty, and a culture of silence, and were analysed as situated within and having implications for inter-linked aspects of communities and environments ${ }^{6,24}$.

Hammell has asserted that "occupational theorists have only rarely sought to explore the needs and perspectives of disabled people in the majority world, and perhaps beliefs, constructs and theories of occupation would look different if we did"7:31. In particular, there is a dearth of participatory research within occupational science and therapy that collaborates with children with disabilities from the Global South as knowledge producers. Within this study, participatory engagement with children with disabilities as coresearchers, facilitated through the use of various occupations, supported challenging dominant assumptions related to disability where experiences of injustices were not as much about autonomy and independence, but also the need for inclusion to participate in occupations and one's community alongside peers. This PAR was carried out in a context that practiced a collectivist way of doing and being, and in turn, child co-researchers wanted to create a group video instead of individual videos. This collectivist way of life also informed what occupational issues were forwarded as problematic by child co-researchers, which were predominantly community issues rather than solely individual injustices.

\section{CONCLUSION}

There is no one way of carrying out an occupation-based PAR, as it is a process that needs to be contextually shaped and informed. This PAR process with children with disabilities as co-researchers, incorporated culturally relevant tools and occupations, which facilitated child co-researchers to not only share issues they wanted changed but also challenge the status quo and normalized situations of oppression seen within everyday doing and being. By making transparent how occupation was central to this PAR with children with disabilities, we urge occupation-based researchers to situate 'occupation' both as a means and an end to socially transformative research practices.

\section{ACKNOWLEDGEMENTS}

This paper was completed as a part of the first author's PhD thesis funded by the Ontario Trillium Doctoral Scholarship and the Christian Medical College (CMC) Research Fluid Grant. We are incredibly grateful to all child-coresearchers for their contribution to this work. Special thanks to the first author's PhD supervisory committee Drs. Debra Cameron, Colleen McGrath, and Vinod Joseph Abraham for critical feedback that strengthened the quality of this work. We also thank Mr. Jeshuran Gunaseelan and Mr. Samuel Prasanna Vinoth Kumar, as well as the staff of the Community Health Department of CMC Vellore, for supporting the first author in the data generation process.

\section{AUTHOR CONTRIBUTIONS}

All primary intellectual contributions were made by the first author Dr. Tanya Elizabeth Benjamin-Thomas, including, conceptualizing the topic, conducting literature reviews, developing the ethics application, establishing relationships with collaborators, facilitating meetings with co-researchers, leading the translation and the transcription process, leading the data analysis and interpretation, and leading the writing of the manuscript. The contribution of co-author, Prof. Debbie Laliberte Rudman, was primarily through supervision of the research, theoretical and methodological guidance, reflexive dialogue, and intellectual and editorial support in crafting the work for publication. The contribution of co-author, Dr. David Mark Thomas, was primarily through reflexive dialogue, designing and creating contextually relevant visual illustrations to support participation of child co-researchers, as well as in intellectual and editorial support.

\section{REFERENCES}

I. Galvaan, R. (202I). Generative disruption through occupational science: Enacting possibilities for deep human connection. Journal of Occupational Science, 28(I), 6-18.

https://doi.org//0.1080/I4427591.2020.1818276

2. Farias L, Laliberte Rudman D. A critical interpretive synthesis of the uptake of critical perspectives in occupational science. Journal of Occupational Science. 2016; 23(I): 33-50. https://doi.org//0.1080/14427591.2014.989893

3. Mondaca M. "Doing hope" as a possible way towards a responsive occupational science. Journal of Occupational Science. 2020. https://doi.org/I0.1080/1442759I.2020.1797858

4. Galvaan R. The contextually situated nature of occupational choice: Marginalised young adolescents' experiences in South Africa. Journal of Occupational Science. 2015; 22(1): 39-53. https://doi.org/10.1080/14427591.2014.912124 
5. Angell AM. Occupation-centered analysis of social difference: Contributions to a socially responsive occupational science. Journal of Occupational Science. 2014; 21 (2): 104-II6.

https://doi.org/I0.1080/I4427591.2012.7। I 230

6. Farias L, Laliberte Rudman D, Magalhães L. (2016). Illustrating the importance of critical epistemology to realize the promise of occupational justice. OTJR: Occupation, Participation and Health. 2016; 36(4): 234-243. https://doi.org/ I0.I I77/I5394492 I666556 I

7. Hammell KW. Resisting theoretical imperialism in the disciplines of occupational science and occupational therapy. British Journal of Occupational Therapy. 20I I; 74(I): 27-33.

https://doi.org//0.4276/0308022 I Ix I 2947686093602

8. Hocking. C. Chapter 5, Occupations through the looking glass: Reflecting on occupational scientists' ontological assumptions. In: Occupational science: Society, inclusion, participation. GE Whiteford, C Hocking, Editors. West Sussex, UK: Wiley-Blackwell; 20 12 : 54-66. https://doi.org/10.1002/978I I I828I58I.ch5

9. Magalhães L, Farias L, Rivas-Quarneti N, Alvarez L, Malfitano APS. The development of occupational science outside the Anglophone sphere: Enacting global collaboration. Journal of Occupational Science. 2019; 26 (2): 181-192.

https://doi.org/10.1080/14427591.2018.1530133

10. Kantartzis S, Molineux M. Chapter 4, Understanding the discursive development of occupation: Historico-political perspectives. In: Occupational science: Society, inclusion, participation. GE Whiteford, C Hocking, Editors. West Sussex, UK: Wiley-Blackwell; 2012: 38-49. https://doi.org/10.1002/978I I 18281581.ch4

I I. Pollard N, Sakellariou D, Lawson-Porter A. (2010). Will occupational science facilitate or divide the practice of occupational therapy? International Journal of Therapy and Rehabilitation. 2010; 17(I): 40-47. https://doi.org/10.12968/ijtr.2010.17.1.45992

12. Benjamin-Thomas, TE, Corrado AM, McGrath C, Rudman DL, Hand C. (20I8). Working towards the promise of participatory action research: Learning from ageing research exemplars. International Journal of Qualitative Methods. 2018; 17(I): I- 13. https://doi.org/10.1 177/1609406918817953

13. Crotty $M$. The foundations of social research: Meaning and perspective in the research process. London: Sage; 1998. https://doi.org/10.4324/9781003115700

14. Kemmis S. Chapter 8 , Critical theory and participatory action research. In: The SAGE handbook of action research: Participative inquiry and practice (2nd ed.). P Reason, $\mathrm{H}$ Bradbury, Editors. Thousand Oaks, CA: Sage. 2008: 12 |-138. https://doi.org//0.4|35/978|848607934.nl4

15. Benjamin-Thomas, T. E., \& Rudman, D. L. (2018). A critical interpretive synthesis: Use of the occupational justice framework in research. Australian occupational therapy journal, 65(I), 3-14. https://doi.org/10.1 I I I/1440-1630.12428

16. Trentham B, Cockburn L. (2005). Participatory action research: Creating new knowledge and opportunities for occupational engagement. In Occupational Therapy without Borders: Learning from the Spirit of Survivor. F Kronenberg, SS Algado, N Pollard, Editors. Toronto, ON: Elsevier Churchill Livingston, 2005:440-453.

17. Benjamin, T. E. (2019). Enacting occupation-based transformative research through participatory filmmaking with children with disabilities (Publication No. 6362) [Doctoral dissertation, Western University]. Electronic Thesis and Dissertation Repository, Scholarship@Western.

18. Benjamin-Thomas, T. E., Rudman, D. L., McGrath, C., Cameron, D., Abraham, V. J., Gunaseelan, J., \& Vinothkumar, S. P. (202I). Situating occupational injustices experienced by children with disabilities in rural India within sociocultural, economic, and systemic conditions. Journal of Occupational Science, I-I8.

https://doi-org.ezp.twu.edu/ 10.1080//4427591.2021.1899038

19. Benjamin-Thomas, T., Laliberte Rudman, D., McGrath, C., Cameron, D., Abraham, V. (2019). A participatory filmmaking process with children with disabilities in rural India: Working towards inclusive research. Methodological Innovations, 12, I-I4. https://doi.org/10.1177/2059799119890795

20. Gubrium A, Harper K. Participatory visual and digital methods. Walnut Creek, CA: Left Coast Press; 2013. https://doi. org/I0.4324/978I3I5423012

21. Merriam SB, Johnson-Bailey J, Lee MY, Kee Y, Ntseane G, Muhamad M. (200I). Power and positionality: Negotiating insider/outsider status within and across cultures. International Journal of Lifelong Education. 2001; 20(5): 405-416. https://doi.org/10.1080/02601370I20490

22. Raval W, Martini TS, Raval PH. 'Would others think it is okay to express my feelings?' Regulation of anger, sadness and physical pain in Gujarati children in India. Social Development. 2007; 16(I): 79105. https://doi.org/I0.1 I I I/j. I467-9507.2007.00373.x

23. Njelesani J, Tang A, Jonsson H, \& Polatajko, H. Articulating an occupational perspective. Journal of Occupational Science. 20I4; 2 I (2): 226-235. https://doi.org//0.1080/1442759I.2012.717500

24. Freire, P. Pedagogy of the oppressed. London, England: Penguin Books; 1993

25. Asaba E, Laliberte Rudman D, Mondaca M, Park M. Chapter II, Visual methodologies: Photovoice in focus. In: Qualitative research methodologies for occupational science and therapy. S. Nayar, M. Stanley, Editors. New York: Routledge; 2015: I55- 173. https://doi.org/10.4324/9780203383216-20

26. Farias L, Laliberte Rudman D, Pollard N, Schiller S, Serrata Malfitano AP, Thomas K, van Bruggen H. Critical dialogical approach: A methodological direction for occupation-based social transformative work. Scandinavian Journal of Occupational Therapy. 2019: 26(4): 235-245. https://doi.org/10.1080/1 1038/28.2018.1469666

27. Anees S. Disability in India: The role of gender, family, and religion. Journal of Applied Rehabilitation Counseling. 2014; 45(2): 32 - 38. https://doi.org/I0.1891/0047-2220.45.2.32

28. Crabtree, JL, Wall JM, Ohm D. Critical reflections on participatory action research in a prison setting: Toward occupational justice. OTJR: Occupation, Participation and Health. 2016; 36(4): 244-252. https://doi.org/10.1177//539449216669/32

29. Strega S, Brown L. From resistance to resurgence. In Research as resistance: Revisiting critical, indigenous, and anti-oppressive approaches. L Brown, S Strega, Editors. Toronto, Ontario: Canadian Scholars' Press. 2015: I-16.

30. Phelan SK, Kinsella EA. Picture this... safety, dignity, and voice-Ethical research with children: Practical considerations for the reflexive researcher. Qualitative Inquiry. 2013; 19(2): 81-90. https://doi.org/10.1 177/10778004/2462987

3I. Laliberte Rudman D. Occupational therapy and occupational science: Building critical and transformative alliances. Cadernos Brasileiros de Terapia Ocupacional. 2018; 26(I): 24I-249. https://doi.org/10.4322/2526-89/0.ctoen I 246

32. Njelesani J, Gibson BE, Nixon S, Cameron D, Polatajko H. Toward a critical occupational approach to research. International Journal of Qualitative Methods. 2013; 12: 207-220.

33. Ramugondo EL. Occupational consciousness. Journal of Occupational Science. 20I5; 22(4): 488-50I.

https://doi.org/I0.1080/I442759I.2015.10425I6

34. Durocher E, Rappolt S, Gibson BE. Occupational justice: Future 
directions. Journal of Occupational Science. 20I4; 2 I (4): 43 I-442.

https://doi.org/10.1080/14427591.2013.775693

\section{Corresponding Author}

\section{*Tanya Elizabeth Benjamin-Thomas}

Email: tbenjamin4@twu.edu 